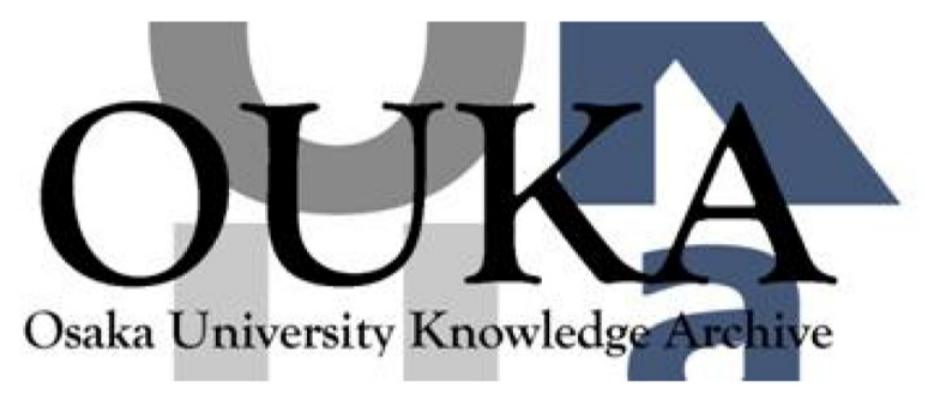

\begin{tabular}{|c|l|}
\hline Title & $\begin{array}{l}\text { Violence Towards Family Caregivers by Their } \\
\text { Relative with Schizophrenia in Japan }\end{array}$ \\
\hline Author(s) & $\begin{array}{l}\text { Kageyama, Masako; Solomon, Phyllis; Yokoyama, } \\
\text { Keiko et al. }\end{array}$ \\
\hline Citation & Psychiatric Quarterly. 89(2) p. 329-p. 340 \\
\hline Issue Date & $2017-10-02$ \\
\hline oaire:version & AM \\
\hline URL & https://hdl. handle.net/11094/75873 \\
\hline rights & \\
\hline Note & \\
\hline
\end{tabular}

Osaka University Knowledge Archive : OUKA

https://ir. Library. osaka-u. ac. jp/

Osaka University 


\section{Violence Towards Family Caregivers by Their Relative with}

\section{Schizophrenia in Japan}

Psychiatric Quarterly, 89(2), 329-340, 2018.

DOI : $10.1007 / \mathrm{s} 11126-017-9537-4$

Masako Kageyama1 \& Phyllis Solomon2 \&

Keiko Yokoyama3 \& Yukako Nakamura4 \&

Sayaka Kobayashi 5 \& Chiyo Fujii ${ }^{6}$

* Masako Kageyama

kageyama@sahs.med.osaka-u.ac.jp

1 Department of Health Promotion Science, Osaka University Graduate School of Medicine, 1-7

Yamadaoka, Suita, Osaka 565-0871, Japan

2 School of Social Policy \& Practice, University of Pennsylvania, 3701 Locust Walk, Philadelphia, PA 19104-6214, USA

3 Department of Nursing, Faculty of Health Sciences, Saitama Prefectural University, 820 Sannomiya,

Koshigaya City, Saitama 343-8540, Japan

4 Department of Psychiatry, Nagoya University Graduate School of Medicine, 65 Tsurumai-Cho,

Showa-ku, Nagoya, Aichi 466-8550, Japan

5 Department of Psychiatry, Saitama Medical University Saitama Medical Center, 1981 Kamoda,

Kawagoeshi, Saitama 350-8550, Japan

6 Department of Psychiatric Rehabilitation, National Institute of Mental Health, 4-1-1

Ogawahigashi-Cho, Kodaira City, Tokyo 187-8552, Japan 


\section{Abstract}

There have been several violence-related deaths in Japan due to family violence by

persons with severe mental illness against their caregivers. However, it is not often

acknowledged that these violent acts are mainly directed at family members. This study

aimed to clarify what acts of violence family caregivers experienced from their relative with

schizophrenia, and how frequently these violent incidents occurred in their lifetime. We also

examined caregivers' thoughts of death about themselves and their relatives, as well as their

consultation efforts and escape from the violence perpetrated by their relative. Of the 277

caregivers, $87.7 \%$ had experienced psychological violence and $75.8 \%$ had experienced

physical violence perpetrated by their relative. Of 210 caregivers who had experienced

physical violence, $26.7 \%$ had thought of murder-suicide and $31.0 \%$ had wished for their

relative's death. Family violence by persons with schizophrenia is not rare but a common

occurrence in Japan and may have fatal consequences.

Key words: violence, parents, schizophrenia, mental disorders, suicide, homicide 


\section{Introduction}

In a 2002 report on violence entitled "World Report on Violence and Health," the

World Health Organization (WHO) declared violence to be a worldwide leading public health

problem and made a plea for the promotion of examining violence as a priority for public

health research [1]. In comparison with other countries, Japan has a low rate of physical

violence and threats of violence inside and outside the home among the general population,

which was $1.1 \%$ for 5 years, whereas it was $17.3 \%$ in the U.K. and $11.4 \%$ in the U.S. [2]. In a

WHO multi-country study of domestic violence, Japan had the lowest rate of reported

intimate partner violence [3].

A number of studies on violence committed by patients with severe mental illness

(SMI), diagnosed with schizophrenia, major depression, and bipolar disorders, report a

moderate relationship between SMI and violence [4]-[7]. However, it is not often

acknowledged that these violent acts are mainly directed at family members [8]. In Japan, the

report based on official criminal records indicated that half of domestic homicides were

committed by persons with SMI [9]. Recently, another type of domestic homicides has been

recognized as a social problem whereby parents have killed their son or daughter with SMI in

order to stop the violence by them against family members [10]. Prior to these incidents,

family members had consulted police officers, public health center staff, and psychiatric 
hospitals on numerous occasions. There are policies and services that focus on intimate partner violence, child abuse, elder abuse, and abuse against persons with physical and intellectual disabilities and mental disorders. However, in Japan there are no specific policies or services to prevent family violence against caregivers by relatives with SMI. There is little awareness of family violence by patients with SMI, and few studies have addressed this issue [11], which may be why to date there are no existing policies or services established. Family violence by patients with SMI may lead to violence-related death including suicide. Victims of intimate partner violence have a higher risk of suicidal attempts [12]. To avoid violencerelated death, this type of violence requires further study.

This issue has remained a private one and not an issue of public concern. In the U.S., family violence by patients with SMI occurs in at least $40 \%$ of families [13]. In Japan, there has been only one investigation of family violence by patients with SMI [14]. The investigation determined that $23.2 \%$ of parents have been a victim of physical violence perpetrated by their adult child with SMI. However, this study employed a small convenience sample $(N=109)$ as well as an undefined period of violence, which makes its findings difficult to interpret. There are few reports about how many families have thoughts of death about themselves and their relatives with SMI precipitated to violence committed by their relatives. Furthermore, there is little information about the families' ways of preventing or resolving these violent acts. Such knowledge is essential for the development of new policies 
and services to prevent family violence perpetrated by relatives with SMI. Research has found that having a diagnosis of schizophrenia is related to violence, especially a higher risk of homicide [4].

The current study focused on caregivers of a relative with schizophrenia and aimed to clarify the types of violence they experienced from their relative with schizophrenia, and how often the violence had occurred in their lifetime. In addition, we examined how often these caregivers had thoughts of their own or their relative's death and their means of attempts to resolve the violence.

\section{Methods}

\section{Data collection and study sample}

The present analyses are part of a larger study "Japanese Family Violence and Mental Illness" that examined the rate of family violence and related factors among caregiving family members and siblings in 866 households belonging to 27 family support groups in one prefecture in Japan. A survey designed for purposes of this study was distributed among the membership by group leaders to 768 of the 866 households. The distribution procedure was determined by the group leader. The leaders did not distribute to 118 households because of the respondents' health or family issues. The present analysis focused on the primary family caregivers of patients with schizophrenia. This subsample was determined from the caregiving family members' questionnaires. Of 482 returned questionnaires, 463 caregiving 
family members in 346 households were valid. Invalid questionnaires for purposes of the present analyses included those with over 50\% missing data $(n=7)$, those in which respondents provided multiple copies of the same questionnaire (the one with fewer missing items was selected; $n=9$ ), and those returned for two different patients by different parents from the same household (the questionnaire from the primary caregiver who cared for the most violent patient was chosen for further analysis; $n=3$ ). Sixty-three percent of the 463 respondents were mothers and $31.8 \%$ were fathers. The average age was 68.8 years $(\mathrm{SD}=$ 8.0) (see Table1). The socio-demographic characteristics of this sample do not differ from members of family groups in other prefectures in Japan [15], [16]. The sample size was reduced to 417 respondents after excluding those who reported that the patients had a diagnosis other than schizophrenia (39), had missing data on diagnosis (4), missing data about caregivers (7), and on all violence items (3). Moreover, to avoid duplicate caregivers for the same patient in a given household, 146 respondents who were not the primary caregiver were excluded from the analyses. Therefore, for the purposes of the present analyses the sample was comprised of 277 primary caregivers from 277 households. When comparing the excluded from the included sample, there were significant differences in relationships to the patients (mother $20.5 \%$, father $75.8 \%$, and others $3.8 \%$ and mother $84.1 \%$, father $11.9 \%$, and others $4.0 \%$, respectively; chi sq., $p<0.0001)$, but no significant difference in age ( $t$-test, $p=0.277)$. 


\section{Measures}

\section{Family violence}

As there are no standard measures of family violence by persons with SMI, we created 14 items about acts of family violence based on interviews with 14 caregivers regarding their relative with schizophrenia. After the items were developed, they were reviewed again by three of the 14 interviewees for purposes of face and content validity. We did not include violent acts that interviewees did not mention, such as sexual violence. We asked respondents to indicate the occurrences of violence in their lifetime and in the past year. The frequency of each violence item was measured by the following response categories: never, 1-4 times, 5-99 times, and 100 times or more (only lifetime). In the present analyses, we used lifetime frequency only. We operationally defined these violence experiences in reference to ones employed in the intimate partner violence scholarly literature [17]. In the current study, psychological violence was defined as the use of verbal and nonverbal communication to harm another person psychologically or emotionally. Physical violence was defined as the use of physical force with the potential for causing death, disability, injury, or harm. Based on these definitions, as shown in Table 2, we categorized these 14 items into psychological (no. 1-6) and physical violence (no. 7-14). Then, we categorized responses into three types of violence experienced: "never experienced violence" (no experience of violence recorded in the two categories), "psychological violence only" 
(only psychological violence), and "physical violence" (any physical violence with and without psychological violence).

\section{Thoughts of death}

We created three items regarding thoughts associated with violence-related death, including suicide, murder-suicide, and death of the patient: "Have you had suicidal thoughts due to violence by the patient?", "Have you had thoughts of murder-suicide with the patient due to his/her violence?," and "Have you wished for the patient's death due to his/her violence?" We asked respondents to indicate yes or no to these three items.

\section{Consultation efforts and escape}

We inquired about consultation with others regarding the violence as well as temporarily living apart due to violence by their relative with mental illness. Regarding consultation efforts, we asked "Have you ever consulted with someone other than family members about the patient's violence?" and whether consultation was sought from any of the following: psychiatrist, co-medical staff, family groups, public health center staff, police officers, staff of a private mental health consultation agency, school teachers, or co-workers. With regard to living apart temporarily, we asked "Have any of your family members lived apart from the patient for a certain time period because of the violence?" and "Who left the home environment?"

\section{Data analysis}


We calculated the distribution of items about family violence in terms of two categories: psychological and physical violence. Next, we focused only on those who had experienced some type of violence, excluding parents who "never experienced violence" from the analysis. We compared the three items about thoughts of death in relation to psychological and physical violence using Fisher's exact test. Finally, we focused only on those who had experienced physical violence and examined consultation efforts and escape from the violence. All analyses were conducted using SAS Version 9.4 (SAS Institute Inc., Cary, NC, USA).

\section{Results}

\section{Sample description}

The demographic data are shown in Table 1 [18]. Of the 277 primary caregivers, $84 \%$ were mothers. Eighty-six percent of primary caregivers lived with the patient and almost half lived on a US\$20K to $40 \mathrm{~K}$ family annual income. Sixty-four percent of the patients were male. The average age of the patient was 40 years old, with a mean of 20 years since onset of the illness, and an average 2.3 hospitalizations in their lifetime. Most had good adherence to treatment. Almost $70 \%$ received grade 2 disability pension, which indicates a severely limited ability in skills of daily living. Over half of the patients did not attend rehabilitation services and stayed at home for most of the day. 


\section{Frequency of types of violence and caregivers' reaction to experiencing physical violence}

Table 2 displays the distribution of the 14 items of violence. Psychological violence (1-6) occurred for 243 primary caregivers $(87.7 \%)$ and physical violence (7-14) occurred for 210 primary caregivers $(75.8 \%)$. Based on these types of violence, the sample of 277 primary caregivers was classified into one of three categories: never experienced violence $(n=26$, 9.4\%), only psychological violence (ever; $n=41,14.8 \%$ ), and physical violence (ever; $n=$ $210,75.8 \%)$

We focused on the 210 primary caregivers who had experienced physical violence. Of these respondents, $149(71.0 \%)$ had consulted with someone outside of the family. Almost $81 \%$ had consulted with the relative's psychiatrists, $47.4 \%$ with co-medical staff, $84.4 \%$ with family groups, $57.6 \%$ with public health center staff, $45.6 \%$ with police officers, $35.5 \%$ with staff of private mental health consultation agencies, $8.5 \%$ with schoolteachers, and $2.3 \%$ with co-workers.

Of the primary caregivers who had ever experienced physical violence, 47 (27.2\%) had lived apart from the patient for a certain time period due to the violence. Of 44 primary caregivers (with the exception of three primary caregivers with missing data), 14 reported that the patient lived apart, 11 parents lived apart, 15 siblings lived apart, and in four cases 
other family members lived apart. In $68.2 \%$ of the 44 households, family members other than the patients had left the home and lived apart for a period of time.

As shown in Table 3, 15.7\% of parents who had experienced physical violence had experienced suicidal thoughts, $26.7 \%$ had thoughts of murder-suicide with the patient, and $31.0 \%$ had wished for the patient's death. These thoughts occurred significantly more often for parents who had experienced physical violence than those experiencing only psychological violence $(0.0 \%, 4.9 \%, 4.9 \%)$.

\section{Discussion}

\section{Family violence}

We found that in their lifetime, $87.7 \%$ of primary caregivers had experienced psychological violence and $75.8 \%$ had experienced physical violence perpetrated by their patient relative. Our study's rate of physical violence is higher than the estimated $40 \%$ lifetime rate of family violence by patients with SMI in the U.S. [13]. The significantly higher rate may be due to the current study including only primary caregivers who likely experienced lengthier cohabitation and, consequently, had more frequent contact with the patients. The patients had a severely limited ability in skills of daily living (almost $70 \%$ of them received grade 2 disability pension) and stayed at home without attending rehabilitation services. Cohabitation [19], [20] and severity of illness [7], [21] have been found to be risk 
factors for family violence by relatives with SMI. Although Japan is a less violent country than many other countries, caregivers who support their ill relative may be at a higher risk of violence than in other countries due to higher cohabitation rates. This situation is likely due to both cultural reasons of family obligation and to insufficient community services for persons with mental disorders with severe grade disability who are unable to live independently and to attend rehabilitation facilities on their own.

\section{Caregivers' thoughts of death due to physical violence}

Of primary caregivers who had experienced physical violence, over a quarter had thoughts of murder-suicide or the patient's death. These rates were higher than parents' thoughts of suicide $(20.4 \%)$, which may be because family members recognized that even if they committed suicide, this would not be a resolution to the violence, as the patient would likely target another family member. Professionals need to be cognizant of the potential for violence in this patient population and take special note of the risk of violence within the family environment where the relative with schizophrenia resides.

\section{Implications for practice and policy}

\section{Policy}

This study revealed that three-quarters of primary caregivers had experienced physical violence, and over a quarter of them had thoughts of murder-suicide or the patient's death. Mental health providers need to be aware that family violence among those with a member 
with mental illness is not rare but a common occurrence in Japan. Over $70 \%$ of primary caregivers who experienced physical violence had consulted others, especially psychiatric clinics or hospitals, family groups, public health centers, and the police. In two actual tragedies in Tokyo in 2014 and Wakayama in 2015, fathers had consulted hospitals, public health centers, and the police on numerous occasions [22], [23], but the organizations and staff were bureaucratically evasive. The fathers believed that the current system could not help their family and resorted to killing their son or daughter who had an SMI. In the current system, collaboration among organizations regarding physical violence by patients with SMI is very situation specific. Consequently, a policy is necessary that requires official enforceable collaboration among a variety of human service agencies, mental health organizations, and criminal justice organizations rather than relying on individual circumstances and the individual will of those involved.

\section{Family education by medical staff}

As this study indicates, psychiatrists and co-medical staff were often consulted about family violence. As such, medical staff likely play a vital role in preventing family violence.

Almost half of the patients with SMI had blamed the parents for their illness at some point [14]. Parents, especially mothers, tend to experience self-blame for their child's diagnosis [24] and may think that they deserve their child's violence. Therefore, parents may be willing to endure the violence up to a certain limit. When they reach that limit, as in a few incidents 
where fathers have killed their adult child with SMI to protect other family members, they may resort to extreme measures. Unfortunately, such situations are often due to parents being at a loss as to how to handle violent behavior of their child [25]. Medical staff are in a good position to teach parents and caregivers about the possibility of family violence and ways to de-escalate such situations and to cope with the stress of these incidents. Education prior to the occurrence of a violent incident may enable parents not to become obsessed with selfblame and to enhance their understanding of the illness as well as the means to manage it.

\section{Living apart to resolve family violence}

Of the primary caregivers who experienced physical violence, over a quarter reported that someone in the household had lived apart from the patient for a certain time period due to the acts of violence. In almost $70 \%$ of the 44 households, family members, rather than the patients, left their home temporarily. Siblings in particular left the family home and were not able to live with their parent(s). This separation may cause painful memories for healthy siblings. However, the fact that over a quarter of primary caregivers selected this option as a means to manage and avoid physical violence shows that leaving the home is a strategy for resolving such situations in the current system in Japan. When family members reside outside the home, they require extra financial resources. This solution may cause a health disparity based on economic inequality. Therefore, publicly funded respite programs for families [26] are needed to avoid serious consequences. In-home treatment 
teams that provide support and education may be another alternative. However, in the long term, instead of living with their parents, patients with SMI need residential services with professional support or combined programs of housing assistance and supportive services, such as permanent supportive housing [27], which are available in other countries.

\section{Limitations and further research}

Regarding the study's limitations, the majority of the sample respondents were

mothers who care for their sons, which is representative of the membership of family groups in Japan. This limitation is also equally true of most studies of family support and education groups in the U.S. [28]. Women continue to be the primary caregivers and are also more likely to volunteer for research [29]. Given that respondents were members of support groups, most had consulted with other family group members about the patient's violence.

Consequently, the respondents in this sample may manage the violence more effectively than other family caregivers who have not joined family groups. Thoughts of death and helpseeking behavior may be worse for parents who are not members of such groups and do not have support from other group members who share similar experiences; therefore, nonmembers may not have the opportunity to benefit from the effective strategies of others. Another limitation is that the study respondents were members of support groups in only one prefecture, which may limit the generalizability of the findings. However, study participants did not differ demographically from members of support groups in other prefectures. 
Furthermore, while we created items regarding family violence and categorized these into psychological and physical violence, they were consistent with those in the domestic violence literature.

In addition, we do not know how strongly thoughts of death are associated with actual homicide or suicide attempts. However, the emotion of hopelessness has been indicated as a predictor of suicide [30]. Consequently, thoughts of death may be a predictor of actual homicide or suicide attempts. We did not ask about the frequency of attempts directly because we felt it was too sensitive a topic for respondents to discuss in depth. Japanese people are likely to be resistant to being asked about suicide because they find such questions socially unacceptable [31]. This study was very limited in its assessment of means of resolving violence perpetrated by a family member with SMI. Future research should be more comprehensive in assessing ways of resolving violent situations in order to enhance understanding how to more effectively prevent such violence and avoid a worst-case scenario.

\section{Conclusion}

Three-quarters of primary caregivers had experienced physical violence, and more than a quarter of them had thought of murder-suicide or the patient's death. Family violence by persons diagnosed with schizophrenia is not rare but a common occurrence in Japan and may lead to the death of a family member. In addition, recent research in the U.S. has found 
that this is not a phenomenon unique to Japan, as an online national survey found that almost half of respondents reported being a victim of violence perpetrated by a relative with SMI [13]. New policies and services are needed in the general medical or health systems to address this issue. Further research examining this type of family violence is necessary to raise awareness and to find solutions and should be promoted in other countries, especially those with higher rates of violence than Japan.

\section{Acknowledgments}

We wish to thank all research participants for their time and care in responding to our questionnaire.

\section{Compliance with Ethical Standards}

Conflict of Interest MK, PS, KY, andYN designed the research project. PS, SK, and CF advised on the interpretations of results. All authors approved the final draft. We disclose receipt of the following financial support for the research, authorship, and/or publication of this article: The first author received financial support from the Uehiro Foundation on Ethics and Education (No. B-016, 2014-2015) for the research and publication of this article.

Ethical Approval All procedures performed in studies involving human participants were in accordance with the ethical standards of the institutional and/or national research committee and with the 1964 Helsinki declaration and its later amendments or comparable ethical standards. Ethical considerations. The Research Ethics Committee of the Faculty of 
Medicine, the University of Tokyo approved the study (February 24, 2014; No. 10,415).. The respondents' anonymity and confidentiality were maintained as we could not determine the identity of the household or the name of the individual respondent. The completion and return of the questionnaire was considered an indication of consent to participate.

\section{References}

[1] E. G. Krug, L. L. Dahlberg, J. A. Mercy, A. B. Zwi, and R. Lozano, "World report on violence and health,” 2002.

[2] Research and Training Institute of the Ministry of Justice, "Dainikai hanzai higai jittai hokioku kokusai hikaku[Second criminal victimes survey, international comparisons]," 2008.

[3] C. García-Moreno, H. A. Jansen, M. Ellsberg, L. Heise, and C. Watts, "WHO multicountry study on women's health and domestic violence against women initial results on prevalence, health outcomes and women's responses," 2005.

[4] S. Fazel, G. Gulati, L. Linsell, J. R. Geddes, and M. Grann, "Schizophrenia and violence: Systematic review and meta-analysis," PLoS Med., vol. 6, no. 8, p. e1000120, 2009.

[5] E. Walsh, A. Buchanan, and T. Fahy, "Violence and schizophrenia: Examining the evidence," Br. J. Psychiatry, vol. 180, no. 1997, pp. 490-495, 2002. 
[6] P. W. Corrigan and A. C. Watson, "Findings from the National Comorbidity Survey on the frequency of violent behavior in individuals with psychiatric disorders," Psychiatry Res., vol. 136, pp. 153-162, 2005.

[7] A. Fleischman, N. Werbeloff, R. Yoffe, M. Davidson, and M. Weiser, "Schizophrenia and violent crime: A population-based study," Psychol. Med., vol. 44, no. 14, pp. 3051-3057, 2014.

[8] H. J. Steadman, E. P. Mulvey, J. Monahan, P. C. Robbins, P. S. Appelbaum, T. Grisso, L. H. Roth, and E. Silver, "Violence by people discharged from acute psychiatric inpatient facilities and by others in the same neighborhoods.," Arch. Gen. Psychiatry, vol. 55, no. May, pp. 393-401, 1998.

[9] Research and Training Institute of the Ministry of Justice, "Kateinaino judaihanzaini kansuru kenkyu [Research about domestic serious crimes],” 2013.

[10] Yomiurishimbun, "Kono syogai byoki nayami satsugai [Killing children with disabilities and illness by their worried parents]," 2017, Tokyo, p. 1, Apr-.

[11] P. L. Solomon, M. M. Cavanaugh, and R. J. Gelles, "Family violence among adults with severe mental illness: a neglected area of research.," Trauma. Violence Abuse, vol. 6, no. 1, pp. 40-54, 2005.

[12] K. Devries, C. Watts, M. Yoshihama, L. Kiss, L. Blima, N. Deyessa, L. Heise, J. Durand, J. Mbwambo, H. Jansen, Y. Berhane, M. Ellsberg, C. Garcia-moreno, and W. 
H. O. M. Study, "Violence against women is strongly associated with suicide attempts : Evidence from the WHO multi-country study on women' s health and domestic violence against women,” Soc. Sci. Med., vol. 73, no. 1, pp. 79-86, 2011.

[13] T. Labrum and P. L. Solomon, "Rates of victimization of violence committed by relatives with psychiatric disorders," J. Interpers. Violence, p. Advance online publication, 2015.

[14] M. Matsuyama, N. Morita, and Y. Ogai, "Seishin syogaisya omotsu oyano seishinteki kenko oyobi koreni kakawaru yoin [Mental health of parents of the mentally disabled and its related factors: Focusing on parent abuse by the mentally disabled children]," Japanese J. Addict. Fam., vol. 29, no. 1, pp. 50-59, 2013.

[15] Zenkaren, "Seishin syogaisya kazokuno kenkojokyoto fukushi niizu 1997[Health status and social welfare needs of families with people with mental disorders 1997]," Tokyo, 1997.

[16] Zenkaren, Daiyonkai zenkoku kazoku niizu chosa hokokusyo [Forth national survey for families]. Tokyo: Zenkaren, 2006.

[17] M. Breiding, K. Basile, S. Smith, M. Black, and R. Mahendra, Intimate partner violence surveillance: Uniform definitions and recommended data elements, Version 2. Atlanta: National Center for Injury Prevention and Control, Centers for Disease Control and Prevention, 2015. 
[18] XXX, "Family violence experienced by patients with schizophrenia," Figshare. doi.org/10.6084/m9.figshare.5016599

[19] R. L. Binder and D. E. McNeil, "Victims and families of violent psychiatric patients.," Bull. Am. Acad. Psychiatry Law, vol. 14, no. 2, pp. 131-139, 1986.

[20] S. E. Estroff, J. W. Swanson, W. S. Lachicotte, M. Swartz, and M. Bolduc, "Risk reconsidered: Targets of violence in the social networks of people with serious psychiatric disorders," Soc. Psychiatry Psychiatr. Epidemiol., vol. 33, no. Suppl 1, pp. S95-102, 1998.

[21] R. W. Swan and M. Lavitt, "Patterns of adjustment to violence in families of the mentally ill," J. Interpers. Violence, vol. 3, no. 1, pp. 42-54, 1988.

[22] Asahi Shimbun, "Boryoku furuu sannan satsugai [Decision for father who killed his third son to protect his wife and daughter]," Tokyo, 04-Dec-2014.

[23] Asahi Shimbun, "Seishin shogai, boryoku no sueni chojo satsugai [Killed daughter with mental disorder due to violence]," Osaka, 25-Nov-2015.

[24] I. Kawazoe, “Togoshichosho omotsu hahaoya no taisyo katei [Coping process of mothers of children with schizophrenia]," Japan Acad. Nurs. Sci., vol. 27, no. 4, pp. 63-71, 2007. 
[25] M. C. Hsu and C. H. Tu, “Adult patients with schizophrenia using violence towards their parents: A phenomenological study of views and experiences of violence in parent-child dyads," J. Adv. Nurs., vol. 70, no. 2, pp. 336-349, 2014.

[26] Y. H. Jeon, H. Brodaty, and J. Chesterson, "Respite care for caregivers and people with severe mental illness: literature review," J. Adv. Nurs., vol. 49, no. 3, pp. 297$306,2005$.

[27] D. J. Rog, T. Marshall, R. H. Dougherty, P. George, A. S. Daniels, S. S. Ghose, and M. E. Delphin-Rittmon, "Permanent supportive housing: assessing the evidence," Psychiatr. Serv., vol. 65, no. 3, pp. 287-294, 2014.

[28] L. B. Dixon, A. Lucksted, D. R. Medoff, J. Burland, B. Stewart, A. F. Lehman, L. J. Fang, V. Sturm, C. Brown, and A. Murray-Swank, “Outcomes of a randomized study of a peer-taught Family-to-Family Education Program for mental illness.," Psychiatr. Serv., vol. 62, no. 6, pp. 591-597, 2011.

[29] National Alliance for Caregiving, "On pins \& needles- Caregivers of adults with mental illness," Bethesda, MD, 2016.

[30] A. T. Beck, G. Brown, R. J. Berchick, B. L. Stewart, and R. A. Steer, "Relationship between hopelessness and ultimate suicide: A replication with psychiatric outpatients," Am. J. Psychiatry, vol. 147, no. 2, pp. 190-195, 1990. 
[31] S. Shimizu, K. Kawano, A. Ishihara, Y. Shimura, F. Takasaki, T. Miyazaki, and N. Koizumi, "Jisatsuni kansuru sinri syakaitekiyoinno haakuhohoni kansuru kenkyu [Research about ways to know about psychosocial factors related to suicide]," 2003. 
Table 1. Demographic Characteristics of Caregivers of Patients With Schizophrenia and Their Patient Relative.

\begin{tabular}{|c|c|c|c|}
\hline \multirow{2}{*}{\multicolumn{2}{|c|}{$\begin{array}{l}\text { Caregivers } \\
\end{array}$}} & \multicolumn{2}{|c|}{$n=277$} \\
\hline & & \multicolumn{2}{|c|}{$n(\%) / M \pm S D$} \\
\hline \multirow[t]{5}{*}{ Relationship } & Father & 33 & $(11.9)$ \\
\hline & Mother & 233 & $(84.1)$ \\
\hline & Spouse & 3 & $(1.1)$ \\
\hline & Sisters & 5 & $(1.8)$ \\
\hline & Others & 3 & $(1.1)$ \\
\hline Age (years) & Average & \multicolumn{2}{|c|}{$68.6 \pm 7.7$} \\
\hline \multirow{2}{*}{$\begin{array}{l}\text { Cohabitation } \\
\text { with patient }\end{array}$} & Yes & 237 & $(86.5)$ \\
\hline & No & 37 & $(13.5)$ \\
\hline \multirow[t]{4}{*}{ Household income ${ }^{a}$} & Less than & 73 & $(26.8)$ \\
\hline & US\$20K & & \\
\hline & US $\$ 20 \mathrm{~K}$ to $40 \mathrm{~K}$ & 134 & $(49.3)$ \\
\hline & Over US\$40K & 65 & $(23.9)$ \\
\hline \multirow{2}{*}{$\begin{array}{r}\text { Membership of } \\
\text { family group } \\
\end{array}$} & Member & 253 & $(92.0)$ \\
\hline & Non-member & 22 & $(8.0)$ \\
\hline \multicolumn{4}{|c|}{ Characteristics of patients } \\
\hline \multirow[t]{2}{*}{ Sex } & Male & 174 & $(64.0)$ \\
\hline & Female & 98 & $(36.0)$ \\
\hline Age (years) & Average & \multicolumn{2}{|c|}{$39.9 \pm 8.9$} \\
\hline Years since onset & Average & \multicolumn{2}{|c|}{$19.5 \pm 9.4$} \\
\hline \multirow[t]{3}{*}{ Psychiatrist visit } & Regularly visit & 238 & $(86.5)$ \\
\hline & Hospitalized & 26 & $(9.5)$ \\
\hline & Not regularly & 11 & $(4.0)$ \\
\hline \multirow{2}{*}{$\begin{array}{l}\text { Medications used as } \\
\text { prescribed }\end{array}$} & Yes & 257 & $(93.4)$ \\
\hline & No & 18 & $(6.6)$ \\
\hline \multicolumn{2}{|c|}{ Number of lifetime hospitalizations } & \multicolumn{2}{|c|}{$2.3 \pm 2.5$} \\
\hline \multirow[t]{4}{*}{ Disability pension $^{b}$} & Grade 1 & 6 & $(2.3)$ \\
\hline & Grade 2 & 185 & (70.3) \\
\hline & Grade 3 & 16 & $(6.1)$ \\
\hline & No certificate & 56 & $(21.3)$ \\
\hline \multirow{2}{*}{$\begin{array}{l}\text { Rehabilitation } \\
\text { attendance }\end{array}$} & Yes & 123 & $(44.9)$ \\
\hline & No & 151 & $(55.1)$ \\
\hline
\end{tabular}

Note. Missing data were excluded.

${ }^{\text {a }}$ Conversion $¥ 100$ to US\$1. 
${ }^{\mathrm{b}}$ Grade 1 (unable to live as usual), grade 2 (severely limited ability for usual living), and grade 3 (limited ability for usual living to participate socially). 
Table 2. Caregivers' Experience of Violence Over the Lifetime.

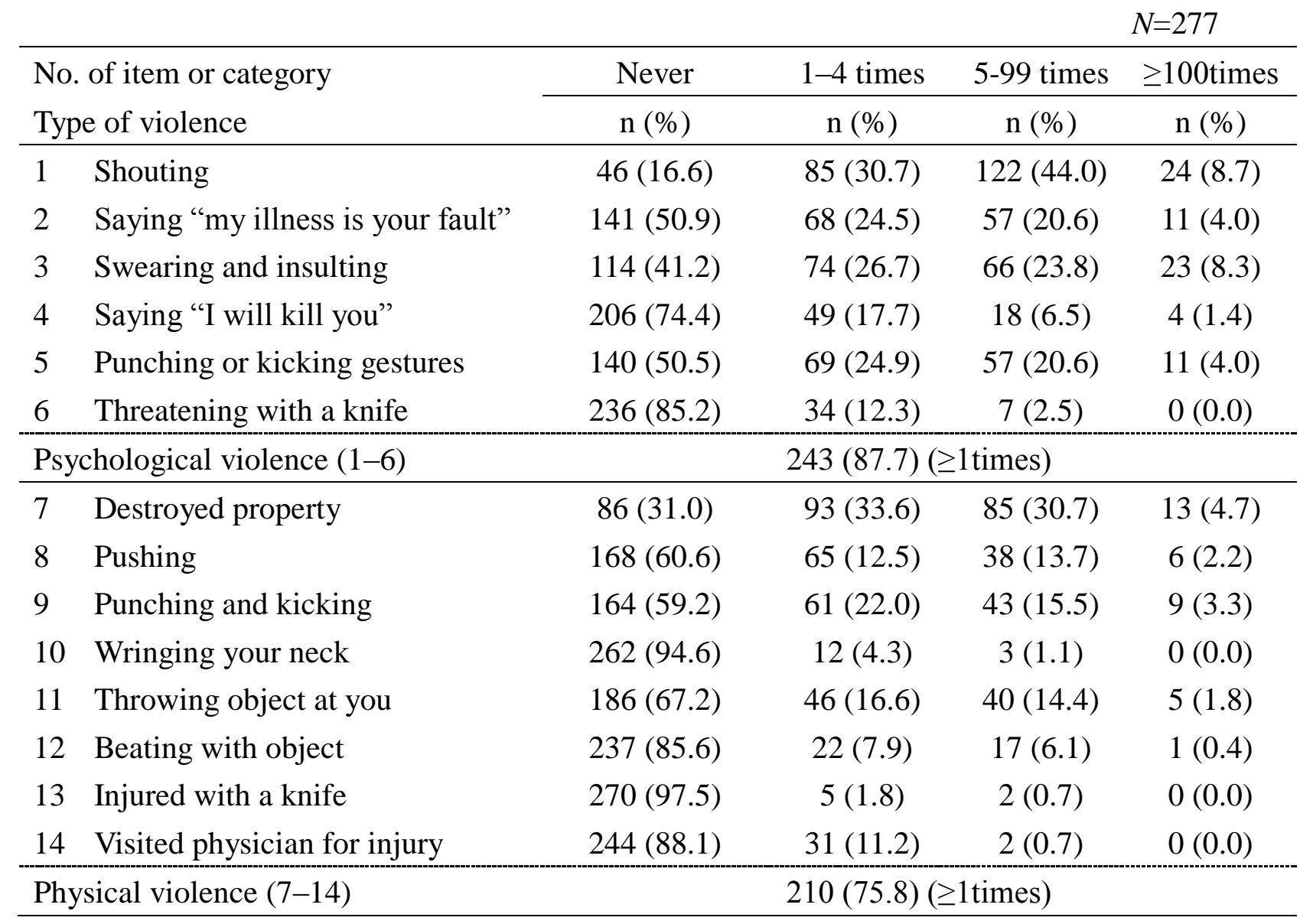


Table 3. Caregivers' Thoughts of Death and Physical Violence.

\begin{tabular}{|c|c|c|c|c|}
\hline \multirow[b]{2}{*}{ Because of violence } & & $\begin{array}{l}\text { Psychological } \\
\text { violence only } \\
\quad(n=41)\end{array}$ & $\begin{array}{l}\text { Physical } \\
\text { violence } \\
(\mathrm{n}=210) \\
\end{array}$ & \multirow[t]{2}{*}{$p$} \\
\hline & & $n(\%)$ & $n(\%)$ & \\
\hline \multirow{2}{*}{$\begin{array}{l}\text { Had suicidal thought } \\
\text { (ever) }\end{array}$} & No & $41(100.0)$ & $177(84.3)$ & \multirow[t]{2}{*}{0.0039} \\
\hline & Yes & $0(0.0)$ & $33(15.7)$ & \\
\hline \multirow{2}{*}{$\begin{array}{l}\text { Had thought of murder- } \\
\text { suicide with the patient } \\
\text { (ever) }\end{array}$} & No & $39(95.1)$ & $154(73.3)$ & \multirow[t]{2}{*}{0.0019} \\
\hline & Yes & $2(4.9)$ & $56(26.7)$ & \\
\hline \multirow{2}{*}{$\begin{array}{l}\text { Had wished for the } \\
\text { patient's death (ever) }\end{array}$} & No & $39(95.1)$ & $145(69.1)$ & \multirow[t]{2}{*}{0.0002} \\
\hline & Yes & $2(4.9)$ & $65(31.0)$ & \\
\hline
\end{tabular}

Note. Missing data were excluded from the analysis.

$p$ : Fisher's exact test. 